\title{
Biological Removal of Malachite Green and Congo red by Some Filamentous Fungi
}

\author{
Ihsan Flayyih Hasan AI-Jawhari ${ }^{1}$, Kadhmiyah Jawad AL-Mansor ${ }^{2}$ \\ ${ }^{1}$ Department of Environment and pollution, Marshes Reserch Centre, Thi-qar University, Iraq \\ ${ }^{2}$ Department of soil and water, Marshes Reserch Centre ,Thi-qar University ,Iraq
}

\begin{abstract}
Four strains of filamentous fungi were studied to a removal of Malachite green $(M G)$ and Congo red $(C R)$. These fungi were Aspergillus niger, Aspergillus flavus, Aspergillus versicolor and P. funigulosum. $P$. funigulosum showed that decolorization activity was higher than other fungi on solid medium containing $M G$ and $C R$. The stastical method obtained that there was no significance between fungi. All these fungi were able to degradation dyes to other metabolites. The dry weight ( Biomass) of P. funigulosum reached to $1.10,1.02$ in mineral salts medium (MSM) with $M G$ and $C R$ respectively, and the stastical methods obtained that there was no significance in dry weights between fungi .
\end{abstract}

Keywords-aquatic life, degradation, dyes ,marsh, efficiency, filamentous fungi, metabolites.

\section{INTRODUCTION}

Various industries discharge effluents containing unused dyes directly into the water bodies causing serios threat to the environment (Zollinger ,1987 ). These dyes effect the life of living organisms in the ecosystem by damaging the health of humans, plants, animals and microorganisms . They also added to the continuously increasing load of environmental water and soil pollutants (Dong et al.,2011) . Treatment of dyeing wastewater was very important before its safe discharging into environment (Hazrat ,2010 ). A large number of physiochemical methods are available for treatment of dyes wastewater but these methods posses a constraint due to their limited versatility, high cost, low efficiency and interference by other wastewater constituent (Banat et al .,1996 ). These physicochemical method also produce a lot of sludge posing a threat as secondary pollutant ( Du et al ., 2011). However, biological methods are available which are eco-friendly and completely mineralize organic pollutants ( Pandey et al., 2007 ). These methods are inexpensive have wide range applicability, low running cost , complete mineralization of dye to anontoxic compound and ecofriendly (Forgacs et al., 2004) . Malachite green (MG) is a water- soluble triphenylmethane cationic dye which is used to color fabrics (Zhou et al ., 2015) . It is also utilized in food and medical industry ( Chowdhury et al ., 2011 ) . Also this dye was toxic on aquatic and terrestrial animals and elicits cytotoxicity on mammalian cell and causes formation of liver tumors (Srivastava et al ., 2004 ). Congo red dye (sodium salt of benzidinediazo-bis-1 naphtylamine-4sulfonic acid, $\left(\mathrm{C}_{32} \mathrm{H}_{22} \mathrm{~N}_{6} \mathrm{Na}_{2} \mathrm{O}_{6} \mathrm{~S}_{2}\right)$ is atypical diazo dye with two chromophoric groups ( azo group) in its structure . It is highly soluble in water and persistent when once discharged into anatural environment (Tapalad et al ., 2008 ; Jalandoni-Buan et al ., 2009 ; Tang et al ., 2011 ). The use of fungi is apromising alternative to replace or supplement current treatments ( $\mathrm{Fu}$ and Viraraghavan ,2001 ; Dos santos et al ., 2004) . Several fungi are able of mineralizing pollutant compounds through their highly oxidative and non- specific ligninolytic enzymes, which are also responsible for the decolorizaion and degradation of many different dyes ( Dos santos et al , 2004). Studies on non-basidiomycetes fungi that degrade dyes are reduced ,neverthe less these fungi are also very efficient for metabolizing awide range of compounds, particularly by demethylation and oxidation ( Cha et al ., 2001 ). Aspergillus species ( EIRahim and Moawad ,2003 ; Jin et al ., 2007 ) Cunninghamella elegans ( Ambrosio and CamposTakaki , 2004 ), penicillium geastrivorus( Yang et al ., 2003 ) ; P. ochrochloron (Shedbalkar et al., 2008 ) ; Fusarium solani and Penicillium funigulosum ( AlJawhari , 2015 ). Thus, the aims of the present study were to investigate the ability of A. niger, A. flavus, A. versicolor and $P$. funigulosum to removal malachite green and congo red

\section{MATERIAL AND METHODS}

\section{Organisms and culture conditions}

A.niger, A.flavus ,A. versicolor and P. funigulosum were obtained from Marshes Research center, Environment laboratory, Thi-qar University ,Iraq . These fungi isolated by Dr. AI-Jawhari from the upper surface of a sediments in Abo-subat marsh in AL-Nasiriya governerate ( south of Iraq) . stock cultures were maintained on the potato Dextrose Agar ( PDA) slant sub cultured periodically and stored at $4 \mathrm{c}^{\mathrm{o}}$.

Chemicals : 
The common names of the two dyes have been used for convenience. Malachite green (MG), Congo red (CR) were from Merch (Germany) . All other chemical used in the present study produced by Himedia (India ) .

Decolorization of MG and CR Dyes in solid medium

A disc $(5 \mathrm{~mm})$ of fungal mycelium was inoculated into the center of petri dishes $(85 \mathrm{~mm})$ with the previously mentioned culture medium with agar. The medium is containing $(2.5 \mathrm{mg} / \mathrm{l})$ of each dye separately in triplicate. The plates were incubated at $25 \mathrm{c}^{\circ}$ for 14 days, after which the mycelium diameter (MD) and decolorization diameter (DD) were determined .The ability of the fungi to decolorize the dye was then expressed as the docolorization index (DI), which was calculated using the following formula :

$\mathrm{DI}=\mathrm{DD} / \mathrm{MD}$

Each test was replicated 3 times .

\section{Biomass production}

One disc (5mm) of A.niger, A.flavus, A. versicolor and P. funigulosum were transferred to $250 \mathrm{ml}$ Erlenmeyer flasks containing $100 \mathrm{ml}$ of autoclaved culture medium (MSM) contained in $\mathrm{g} / \mathrm{l}:$ yeast extract $0.3, \mathrm{k}_{2} \mathrm{HPO}_{4} 0.75$, $\mathrm{KH}_{2} \mathrm{PO}_{4} 0.75, \mathrm{MgSO}_{4} .7 \mathrm{H}_{2} \mathrm{O} 0.05, \mathrm{CaCl}_{2} .2 \mathrm{H}_{2} \mathrm{O} 0.05$ and $\mathrm{FeSO}_{4} .7 \mathrm{H}_{2} \mathrm{O} 0.02$ at $\mathrm{PH} 7.0$ supplemented with $0.5 \mathrm{mg} / \mathrm{l}$ of each dye separately, in triplicate. The flask were incubated at $25 \mathrm{c}^{\circ}$ for 7 days and shaking manually every day. The biomass was determined by calculated the dry mass of mycelia. Mycelia were harvested from the cultivation liquid medium by filtration using whattman No.1 filter paper and dried of $65 \mathrm{c}^{\circ}$ at $30 \mathrm{~min}$ and weighted $(\mathrm{mg} / 10 \mathrm{ml})$.

\section{Biodegradation of dyes in liquid medium}

After incubation (14 days) of one disc (5mm) from A.niger ,A.flavus, A. versicolor and P. funigulosum in mineral salts medium (MSM) . Mycelia were harvested from the cultivation liquid medium by filtration using whattman No.1 filter paper and the filter was used to determined the biodegradation (MG) and (CR) by using FourierTransform Infrared (FTIR) spectroscopy .

\section{Stastical analysis :}

The present study conducted an Anova (analysis of variance ) which was performed on all the treatments and done using the spss (version 10.0 ) package to determin whether or not significance difference .

\section{RESULT AND DISCUSSION}

Decolorization of MG and CR dyes in solid medium The dyes evaluated in this study contain aromatic compounds that are degraded by filamentous fungi during secondary metabolism. The growth and degradation efficiency of the test fungi as determined based on the their decolorization ability in solid medium are shown in Table 1 , Figure 1 , of the 4 fungi cultured on solid medium with $\mathrm{MG}$ and $\mathrm{CR}$.

Table.1:Decolorization of aromatic dyes on solid medium by filamentous fungi

\begin{tabular}{|c|c|c|c|c|c|c|}
\hline \multirow{2}{*}{ Name of fungi } & \multicolumn{3}{|c|}{ Malachite green } & \multicolumn{3}{c|}{ Congo red } \\
\cline { 2 - 7 } & MD* & DD & DI & MD & DD & DI \\
\hline A.niger & 28 & 50 & 1.8 & 65 & 9.0 & 0.14 \\
\hline A.flavus & 26 & 44 & 1.7 & 74 & 4.0 & 0.10 \\
\hline A.versicolor & 28 & 51 & 1.8 & 54 & 17.0 & 0.31 \\
\hline P.funigulosum & 29 & 56 & 1.9 & 80 & 3.5 & 0.40 \\
\hline
\end{tabular}

*: $(\mathrm{mm}), \mathrm{MD}$ : Mycelial diameter , DD: Decolorization diameter, DI : Decolorization index = DD/MD . The mycelia diameter and decolorization diameter were measured $(\mathrm{mm}, \mathrm{n}=3)$ after 14 days of incubation . 


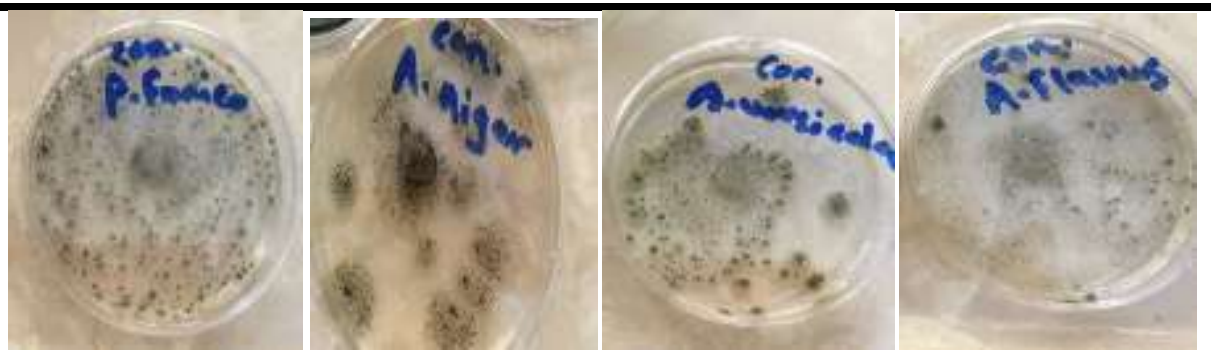

A
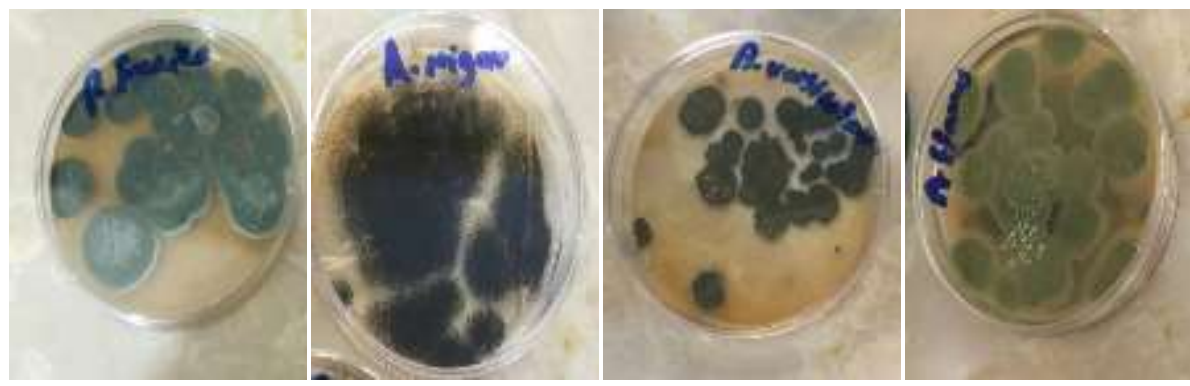

B
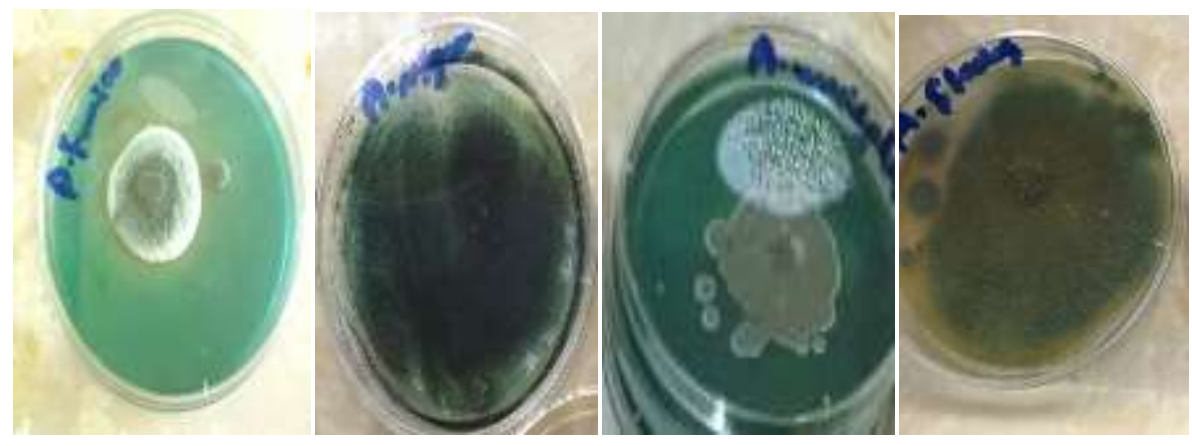

$\mathrm{C}$

Fig.1:Decolorization of Malachite green and Congo red by filamentousfungi on solid medium .

A:Control , B: Congo red , C: Malachite green

$P$. funigulosum showed that decolorization activity was higher than that of remaining 3 fungi, these ability due to that this fungus have unique systems enzymes for breaking complex organic structures into simple fragments, however the mycelia of the $P$. funigulesum was higher than other fungi on solid medium contain MG .In the same time all the remaining fungi can able to decolorization this dye .

Table1 show also that $P$. funigulosum was higher decolorization activity than other fungi on solid medium contain $\mathrm{CR}$ and the mycelia of the $P$. funigulosum was higher than other fungi . The value of decolorization of MG and CR on solid medium by the selected fungi was not considerably higher. The stastical methods obtained that there was no significance between fungi . The same results were obtained by (Chandana et al ., 2008 ), in this study show that when the white rot fungi Cariolus versicolorwas good mycelia growth on solid media contained MB, but the efficiency of decolorization was very low , and in the same time the decolorization index with this fungus reached to 0.11 , but the results obtained by (Rania ,2008) were differ with results in present study , when studied the decolorization of crystal violet and malachite green by using Fusarium solani, this fungus decolorized dyes quickly with the radial growth and the decolorizatin halo of $\mathrm{CV}$ and that of MG occupied nearly the entire diameter of the plate after 3 days of incubation at $30 \mathrm{c}^{\circ}$. The results in present study was similar with the results obtained by (Al-Jawhari , 2015) when show that F.solani and P. funigulosum appear higher ability to decolorization of MB and CV in solid media . In addition the results of study conducted by ( Abo-state et al ., 2011 ) also showed that the ability of pleurotus ostratus to decolorize $\mathrm{MB}$ also increased, so the removal \% increased for awide range of concentrations ( 25-700 mg/l ) $\mathrm{MB}$, and in the same time (Abo-state et al ., 2011) refer that this result due to may attributed to the increasing in production of lignolytic enzymes as the concentration of MB increased due to their stress on the mycelia cells of $P$. ostratus . The results in present study were similar with results obtained by ( Chandana et al ., 2008 ), in this study showen that all the 10 fungi evaluated were grow 
slowly on solid media that contain Malachite green and poor ability to decolorize these fungi, but in the present study, the results were not agreed with the results obtained by ( Hazrat et al ., 2013 ), in this study showen that Alternaria solani is quite tolerant to crystal violet and decolorize and degrade relatively higher concentrations of the dye.

\section{Biomass production}

Growth study revealed that biomass and dye removal are directly proportional, which may be attributed to the fact, the increase of biomass gave more surface area for sorption of the dye molecules available, and may be due to the shaken of flask, this result was agreement with the results of (Mohorcic et al ., 2004 ), In this study showen that the most effective fungus in shaken flask experiment was Bjerkandera adusta, which was able to decolorize the dye from black- blue to yellow color in less than 10 days .

Table 2 explain that the dry weight of $P$. funigulosum was higher than other fungi with $\mathrm{MG}$ and $\mathrm{CR}$, the dry weight of this fungus reached to $1.10 \mathrm{gm}$ with $\mathrm{MG}$ dye , this extraordinary absorption value may have been due to areaction of MG with enzymes secreted by the fungal mycelia ( Chandana et al ., 2008 ). And in the same time the dry weight of $P$. funigolosum reached to $1.02 \mathrm{gm}$ with CR . The stastical methods obtained that there was no significance in dry weights between fungi.
Table.2:Mycelial dry weight of fungal strains in liquid medium containing Malachite green and Congo red.

\begin{tabular}{|c|c|c|}
\hline Fungi & MG & CR \\
\hline A.niger & $0.78^{*}$ & 0.91 \\
\hline A.flavus & 0.70 & 0.85 \\
\hline A.versicolor & 0.69 & 1.01 \\
\hline P.funigulosum & 1.10 & 1.02 \\
\hline
\end{tabular}

* Mean of triplicate , Dry weight calculated with ( gm) The same results were obtaind by ( Muthezilan et al ., 2008 ), in this study showen that the dry weight reached to $0.49 \mathrm{gm}$ with Penicillium citrinum in liquid media containing CV and the low dry weight reached to $0.22 \mathrm{gm}$ with Mucer racemosus and Trichoderma viride. ( Haglund , 1999) refer that in liquid culture, rapid dye decolorization by the fungal strain was observed within $24 \mathrm{~h}$. It was mainly due to the high adsorption of the dye in the mycelium . In subsequent dyes, dye decolorization may be due to production of extrucellular enzymes.

\section{Bioderadation of dyes in liquid medium}

Degradation of MG and CR was confirmed by FTIR analysis of $\mathrm{MG}$ and $\mathrm{CR}$ and its degraded metabolites . FTIR spectrum of MG showed distinct peaks in the finger print region (1500-500 $\mathrm{cm}^{-1}$ ), which corresponds to mone and para substituted benzene ring and were distinct to $\mathrm{MG}$. The peaks were observed at $700,800 \mathrm{~cm}^{-1}$ corresponding to aromatic ring structure. Also peak at $1100 \mathrm{~cm}^{-1} \quad$ corresponds aromatic C-N stretching vibration ( Fig. 2). Fig. 3 showed degraded metabolites by $A$. niger, new peak were appear at $1400,1450 \mathrm{~cm}^{-1}$ for aromatic group, also new peak appear at $3000 \mathrm{~cm}^{-1}$ for $\mathrm{CH}_{2}$ bond at $1600 \mathrm{~cm}^{-1}$ for aromatic ketones. Reduction of peaks at 700,800 and $1500 \mathrm{~cm}^{-1}$ indicated loss of aromaticity of metabolites.

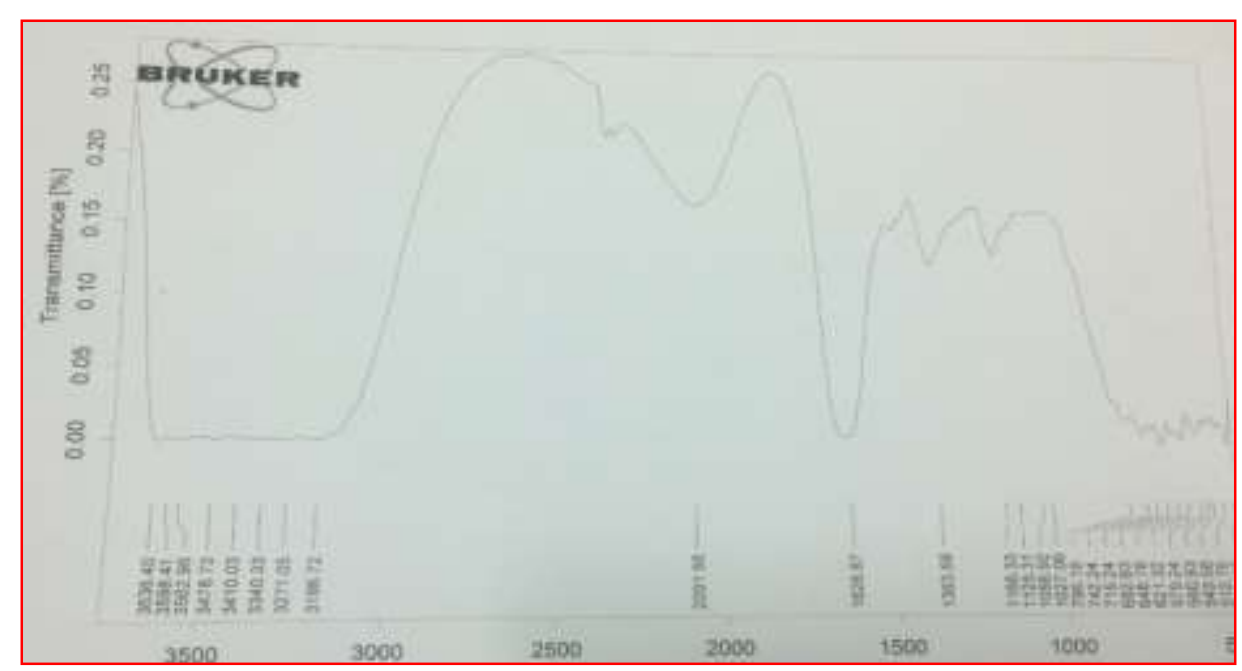

Fig.2: Malachite green (Standard) - uninculated . 


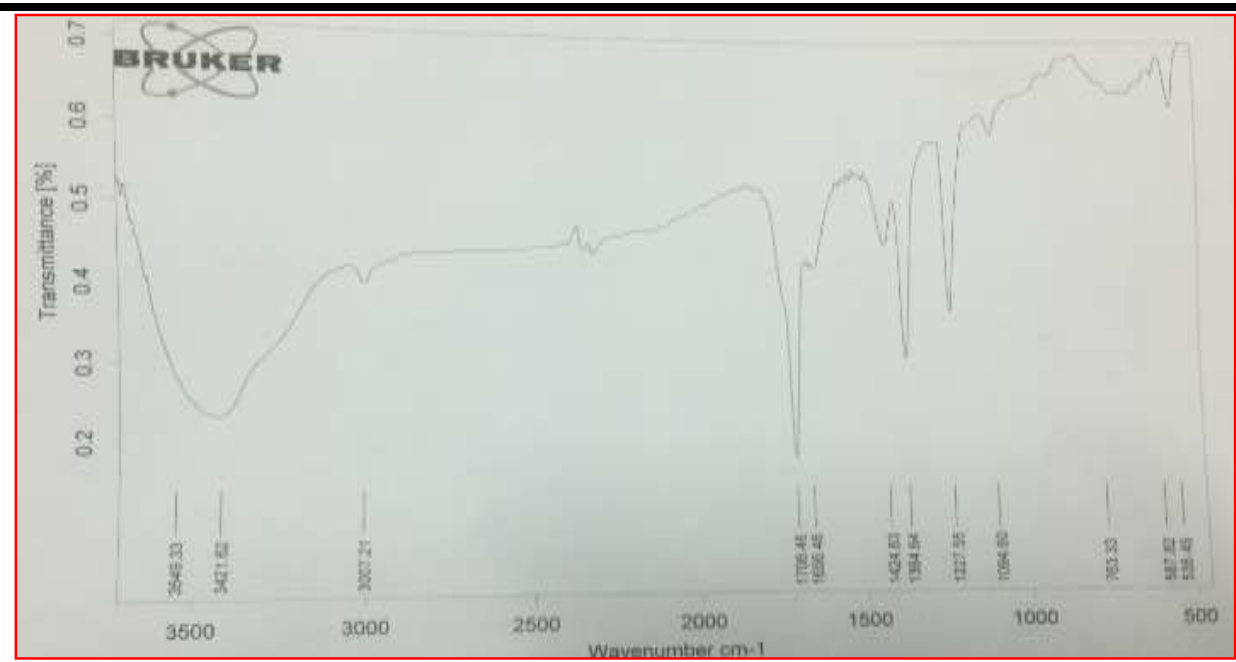

Fig.3: Biodegradation of malachitegreenby A.niger after 14 day incubation .

Fig. 4 showed degraded MG by A. flavus, new peaks also appear at $1200,1300 \mathrm{~cm}^{-1}$ for $\mathrm{CH}_{2}$ stretching band and new peak appear at $1650 \mathrm{~cm}^{-1}$ for aromatic ketones, also Fig. 4 showed reduction of peaks at 700,800 and $1500 \mathrm{~cm}^{-1}$.

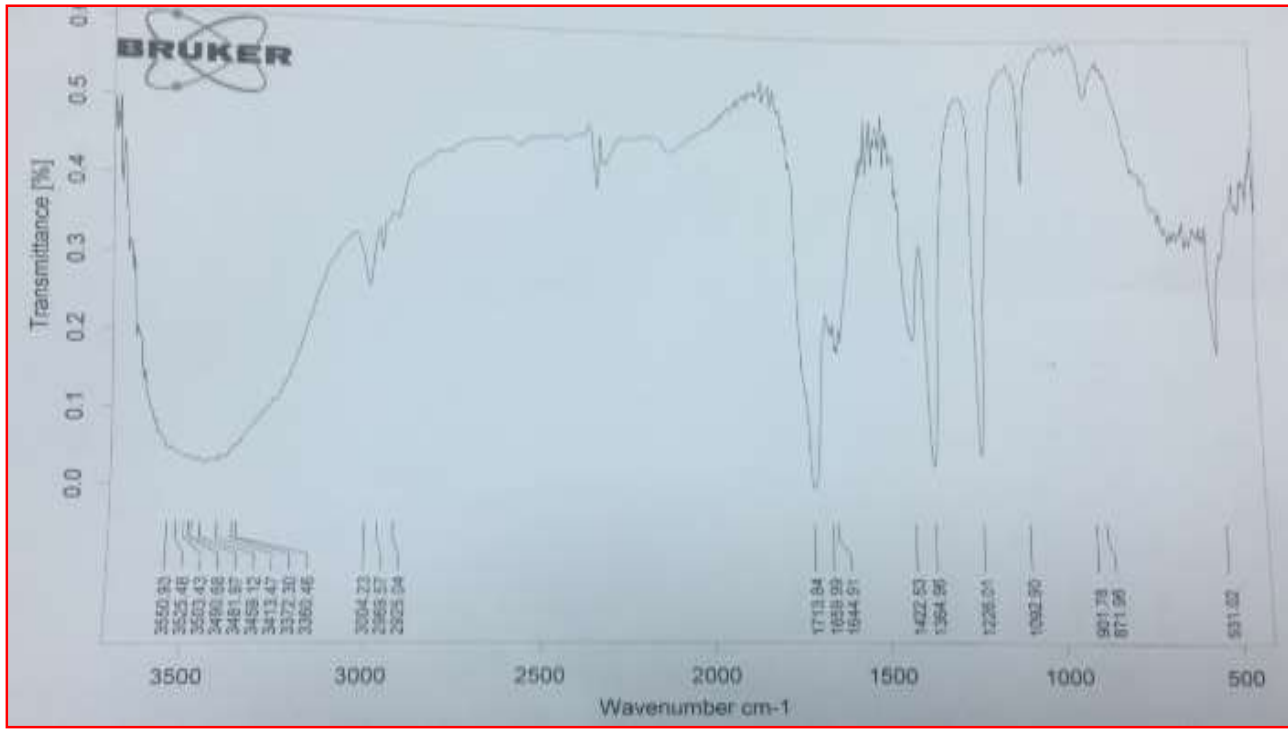

Fig.4: Biodegradation of malachite green by A.flavus after 14 day incubation .

Fig. 5 showed degraded metabolites by A. versicolor, new peaks were appear at 2400 and $3000 \mathrm{~cm}^{-1}$, also many peak were reduction at $700,800,1500 \mathrm{~cm}^{-1}$ and in the same time Fig.5 showed the ability of A. versicolor to degraded MG . Fig. 6 showed reduction of peaks at $700,800,1500 \mathrm{~cm}^{-1}$, this result refer the loss of aromaticity of metabolites and this fungus was able to degraded $\mathrm{MG}$.

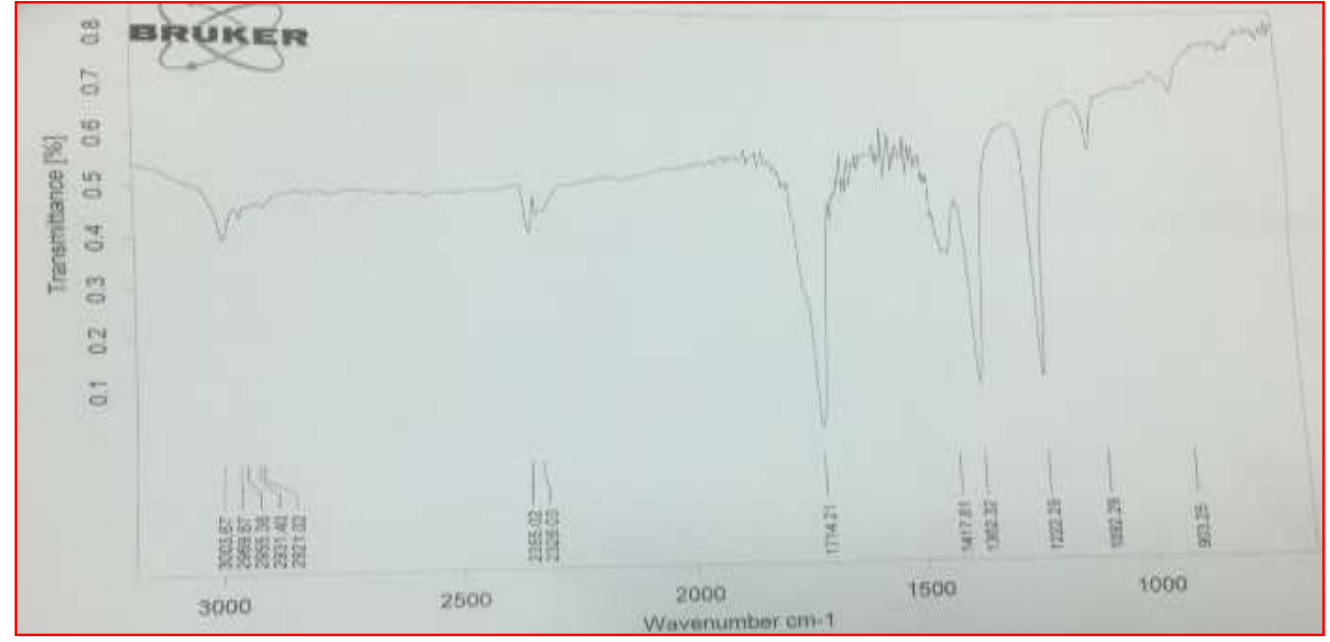

Fig.5: Biodegradation of malachite green by A.versicolor after 14 day incubation . 
Fig. 6 showed degraded metabolites by $P$. funigulosum, new peaks were appear at $1200,1300 \mathrm{~cm}^{-1}$ and new peak appear at $1650 \mathrm{~cm}^{-1}$, also many peaks were reduction at $700,800,1500 \mathrm{~cm}^{-1}$. Fig. 6 showed high ability of this fungus to degraded MG .

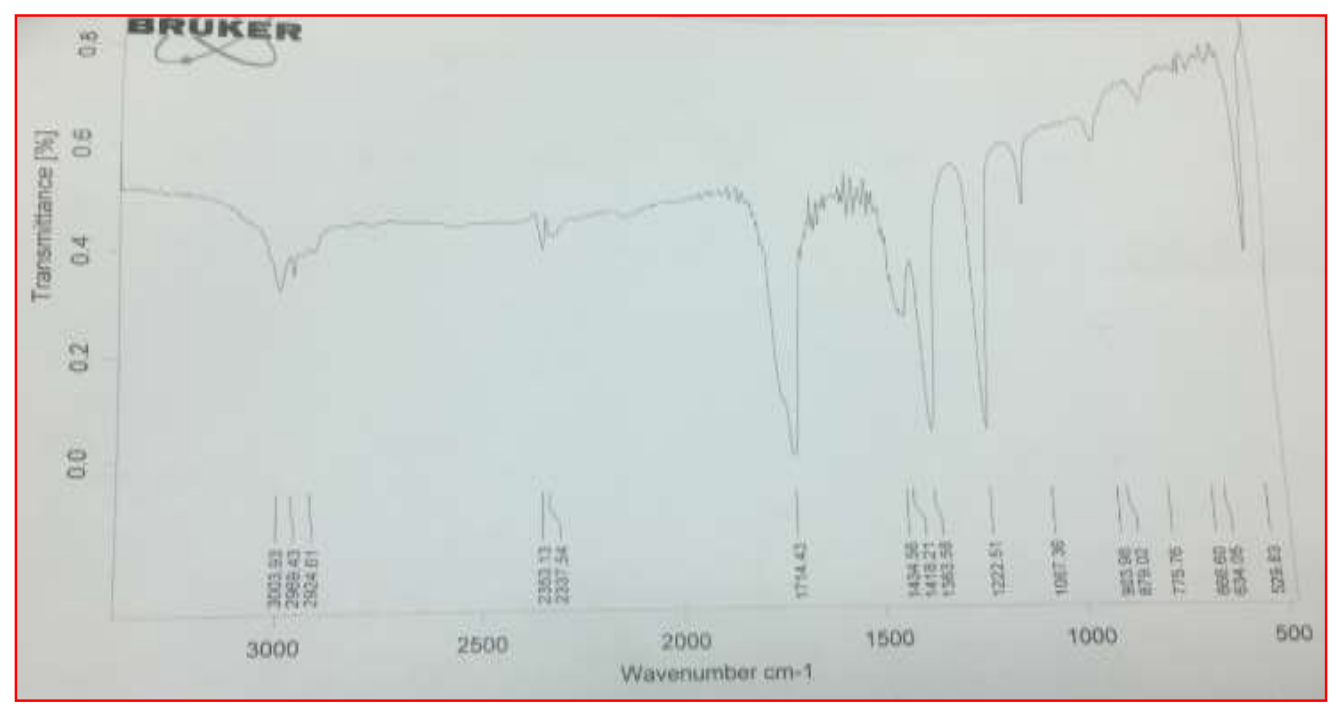

Fig.6: Biodegradation of malachite green by P. funigulosum after 14 day incubation .

Fig. 8 showed the ability of $A$. niger to degraded CR , new peak were appear at $1100,1200,1300 \mathrm{~cm}^{-1}$ and also reduction of peaks at $1500 \mathrm{~cm}^{-1}$ when compared control (Fig. 7) . Fig.9 showed the ability of A.flavus to degraded CR, new peak were observed at $500,1650 \mathrm{~cm}^{-1}$.

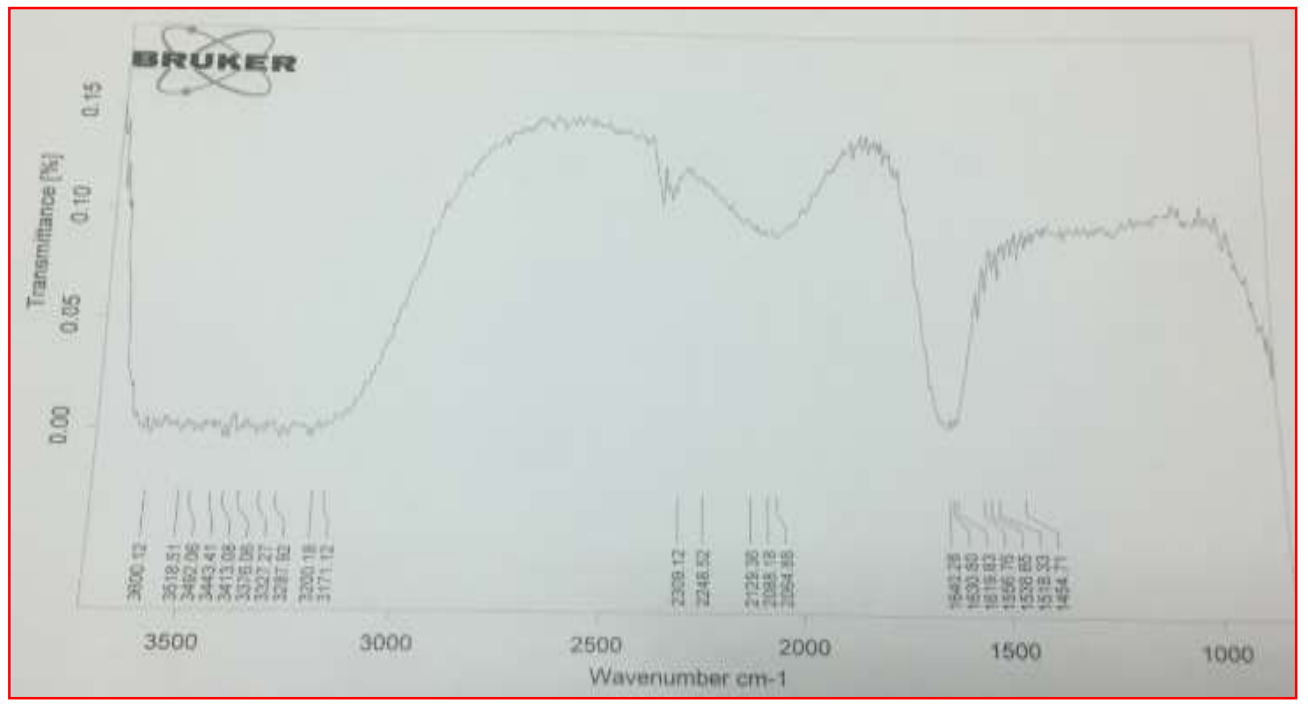

Fig.7: Congo red (Standard)-uninculated . 


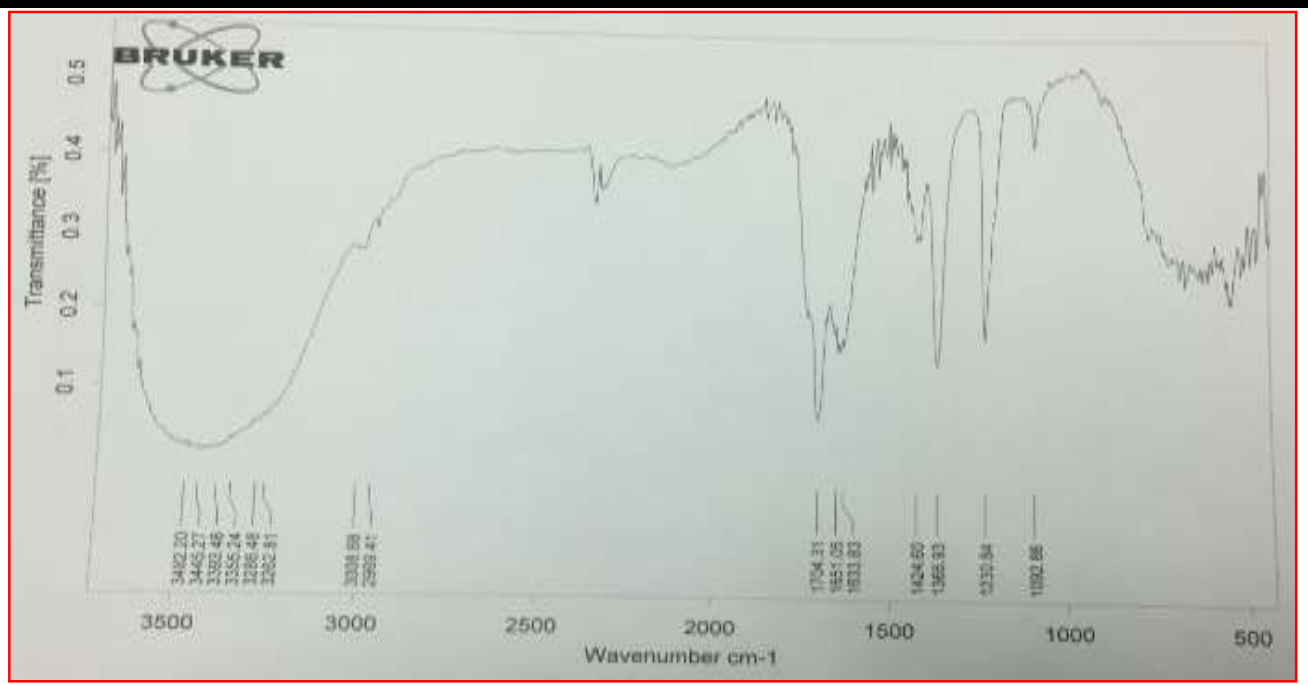

Fig.8: Biodegradation of congo red by A.niger after 14 day incubation.

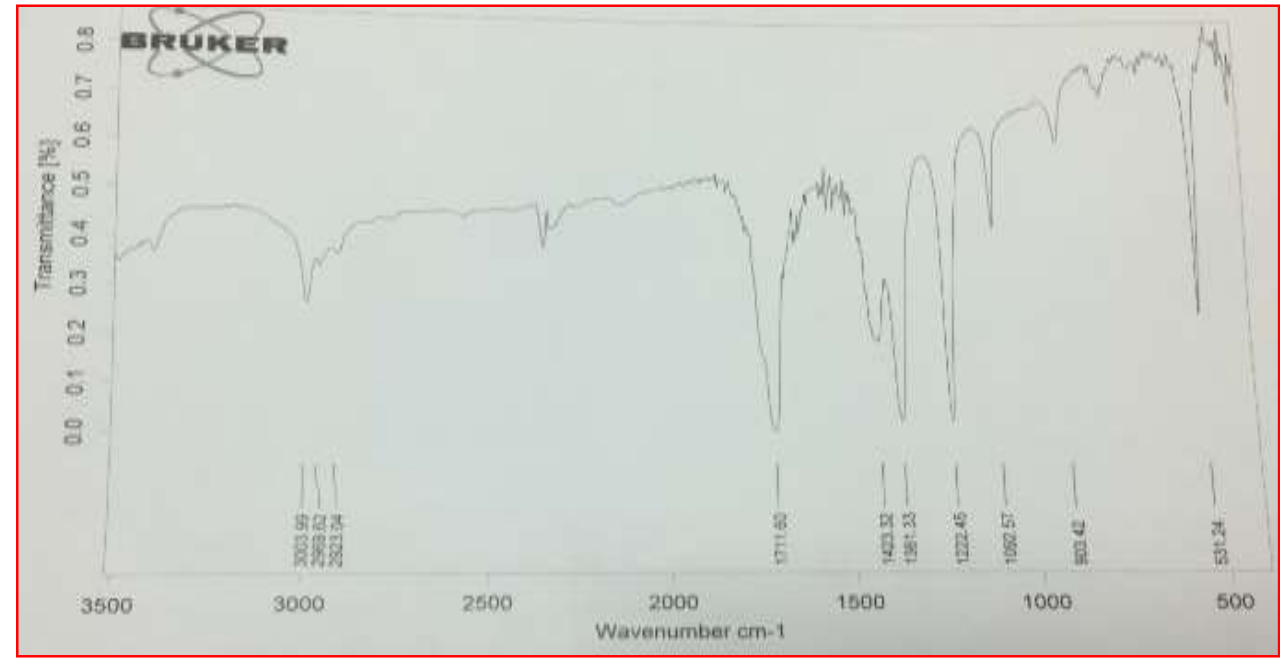

Fig.9: Biodegradation of congo red by A.flavus after 14 day incubation.

Fig. 10 showed the ability of A.versicolor to degraded CR, new peak were observed at $500,1650 \mathrm{~cm}^{-1}$. Fig. 11 showed the ability of $P$. funigulosum to degraded CR , new peak were observed at $500,1650 \mathrm{~cm}^{-1}$. These results are in accordance with previos reports of ( Ayed et al ., 2009; Kalyani et al ., 2009 ; Chaturvedi et al ., 2013 ) (Du et al ., 2011 ) reported that degraded product formed by bio degradation of MG by Pseudomonas aeruginosa NCIM 2074 are non toxic . similarty (arshetti et al ., 2006 ) reported that biodegradation product of MG formed by action of kocuria rosea MTCC 1532 was non toxic .

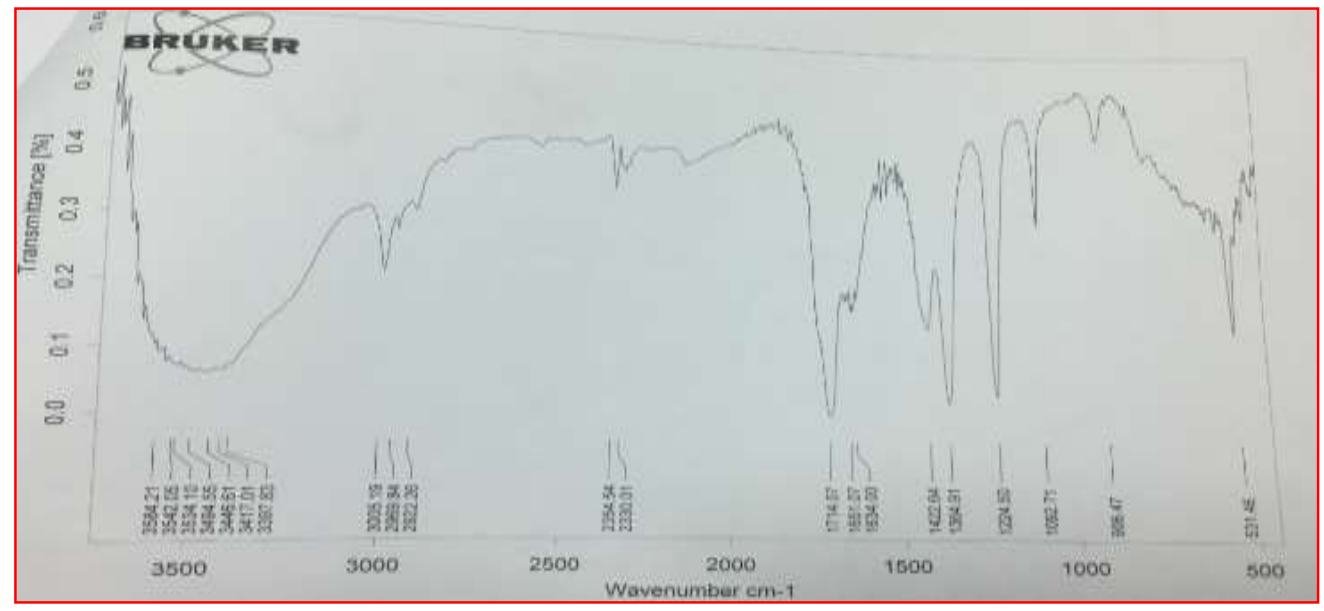

Fig.10:Biodegradation of congo red by A.versicolor after 14 day incubation . 


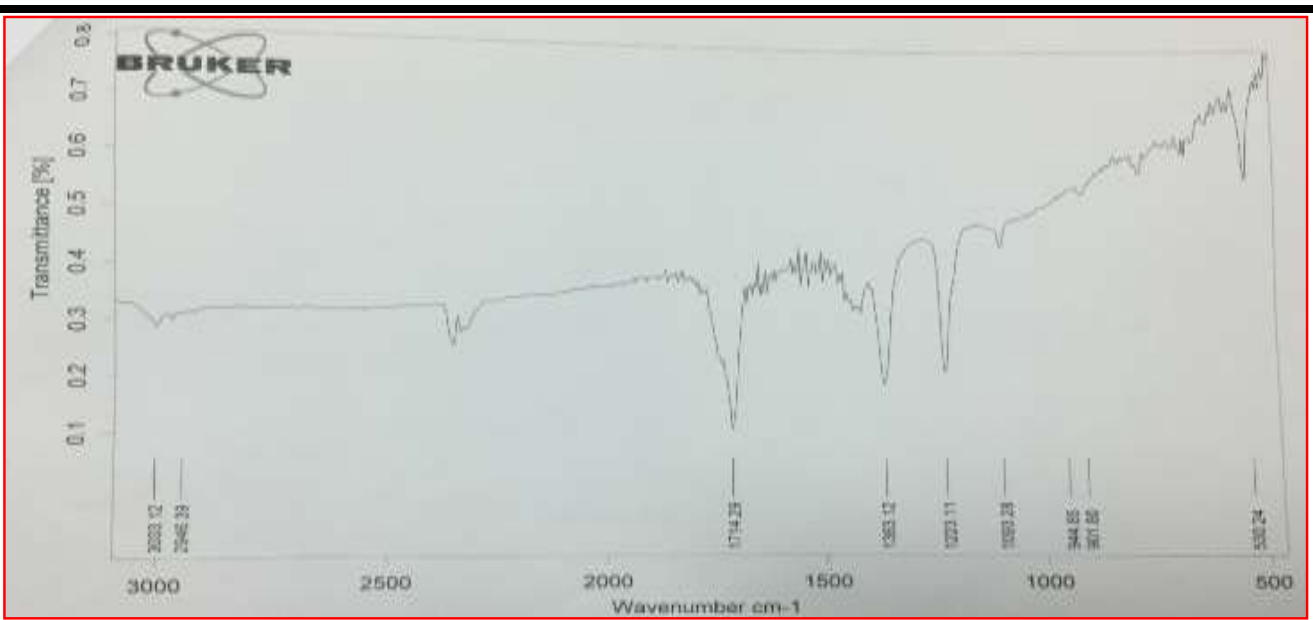

Fig.11: Biodegradation of congo red by P.funigulosum after 14 day incubation .

\section{CONCLUSIONS}

The study concluded that, these fungal strains on their own can offer a costeffective, easily applicable and an environmently sound solution to dye effluents.

Rehabilitation of MG and CR dyes contaminated rivers, Marshes water by the culture of these fungi were promising as it can reduce and removal the dyes pollution.

\section{REFERENCES}

[1] Abo-state ,M. A. M. ; Reyad , B. ; Ali , M. ; Gomaa , O. ; Youssif, E. A. Comparing decolorization of dye by white rot fungi, free enzyme and immobilized enzyme, World. App. Sci. J., 14(10), $1469-1486.2011$.

[2] Al-Jawhari , I. F. H. Decolorization of methylene blue and crystal violet by some filamentous fungi . Int. J. Envirom. Bioremd. Biodeg. 3(2):62-65 .2015.

[3] Ambrosio , S. T. ; Campos -Takaki , G. M. Decolorization of reactive azo dyes by Cunninghamella elegans UCP 542 under cometabolic conditions. Biores . Technol. 91 : 6975.2004.

[4] Ayed,L.;Chieb,K.;Cheref ,A. Biodegradation of triphenylmethane dye Malachite green by Spingomonas paucimobilis . World J.MicrobioIBiotechnol . 25: 705- 711.2009 .

[5] Banat , I. M. ; Nigam , P. ; McMullan , G. ; Marchant, R. ; Singh, D. Microbial decolorization of textile dye containing effluents : a review . Biosour Technol. 58 : 217-227 . 1996.

[6] Cha , C. J. ; Doerge , D. R. ; Cerniglia , C. E. Biotransformation of malachite green by the fungus Cunninghamella elegans . APPI .Environ .Microbiol .67 : 4358-4360 . 2001.

[7] Chandana ,J. ,Ahmed , I.; Geon , W. L. ;Kyung , H. I. ; Hyun ,H. ; Min , W. L. ; Hee-sun, Y. ; Tae-soo , L. Degradotion of three aromatic dyes by white rot fungi and the production of ligninolytic enzymes , Microbiol ., 36 (2), 114 -120.2008.

[8] Chaturvedi , V.; Bhange, K. ; Bhatt, R. ; Verma , P. Biodetoxification of high amounts of malachite green by amultifunctional strain of Pseudomonas mendocina and its ability of metabolize dye adsorbed chicken feathers . J. Env. Chem . Eng. , 1:1205-1213 . 2013.

[9] Chowdhury , S. ; Mishra , R. ;Saha ,P. ; Kushwaha , P. Adsorption thermodynamics, kinctics and isosteric heat of adsorption of malachite green onto chemically modified rice husk. Desalination , 265: 159-168. 2011 .

[10] Conneely , A. ; Smyth , W. F. ; McMullan , G. Metabollism of the phthlocyanin textile dye remazolturquoise blue by phamerochaete chrysosporium . FEMS Microbiol. Lett. J. 179: 333337.1999

[11]Dong, Y. ; Bin, L. U. ; Shuying ,Z. ; Jingxiang , Z. ; Xiaoguang , W. ; Qinghai ,C. Removal of methylene blue from coloured effluents by adsorption onto SBA-15 . , Chemical Technol ,Biotechnol., 86(4), 616 -619 . 2011.

[12]Dos santos , A. Z. ; Neto , J. M. C. ; Tavares , C. R. G. ; da costa, M. G. Screening of filamentous fungi for the decolorization of a commercial reactive dye . J. Basic Microbiol .44 : 288-295 . 2004.

[13]Du , L. N. ; Wang, S. ; Li, G. , Wang , B. ; Jia , X. M. ; Zhao, Y. H. ; Chen, Y. L. Biodegradation of malachite green by Pseudomonas sp. Strain DYI under aerobic condition : Characteristics , degradation products, enzyme analysis and phytotoxicity . Ecotoxicology . 20(2) : 438 -446 .2011 .

[14]El-Rahim , W. M. A. ; Moawad , H. Enhancing bioremoval of textile dyes by eight fungal strains from media supplemented with gelatin wastes and sucrose . j. Basic Microbiol . 43: 367-375 .2003. 
[15]Forgacs , E. ; Cserhati , T. ; Oros , G . Removal of synthetic dyes from wastewaters : a review . Envi. Int. 30 : $953-971$. 2004 .

[16]Fu , Y. , Viraraghavan , T. Fungal decolorization of dye wastewater : a review Biores . Technol .79:251 $-262.2001$.

[17] Haglund , C. Biodegradation of xenobiotic compounds by the white rot fungus Trametestrogii . Msc .Thesis . University of Buenos Aires , Argentina , 1-30. 1999.

[18]Hazrat , H. Biodegradation of synthetic dyes : areview . Water Air Soil pollut, 213: 251-273 .2010

[19] Hazrat , A. ; Mehtab , K. ; Muhammad , I. ; Sohail , A. J. Biological decolorization of Crystal violet by Alternariasolani ., Int. J. of green and Herbal chem. , 2(1), 31-38. 2013 .

[20] Jalandoni-Buan ,A. C. ; Decena-Soliven, A. L. A. ; Cao , E. P. ; Barraquio , V. L. ; Barraquio, W. L. Congo red decolorizing activity under microcosm and decolorization of other dyes by Congo red decolorizing bacteria . Phillip . J. Sci. , 138: 125-132 . 2009 .

[21] Jin , X. C. ; Liu , G. Q. ; Xu , Z. H. ; Tao , W. Y. Decolorization of a dye industry effluent by Aspergillusfumigatus XC6 . Appl .Microbiol .Biotechnol. , 74: 239- 243.2007 .

[22] Kalyani, D. C. ; Telke , A. A. ; Dhanve , R. S. ; Jadhav , J. P. Ecofriendly biodegradation and detoxification reactive red 2 textile dye by newly isolated Pseudomonas sp. SUKI . J. Hazard .Mater . 163(2) : 735-742 . 2009.

[23] Mohorcic, M. ; Friedrich , J. ; Pavko , A. Decolorization of the diazo dye reactive black 5 by immobilized Bjerkanderaadusta in stirred tank bioreactor. Acta . Chem. Solv. , 51 : 619 -628. 2004 .

[24] Muthezhilan , R. ; Yogananth , N. ; Vidhya , S. ; Jayalaksmi , S. Dye degrading mycoflora from industrial effluents , Res. J. Microbio I., 3(3) , 204208.2008 .

[25] Pandey , A. ; Singh , P . , Iyengar , L. Bacterial decolorization and degradation of azo dyes. Int .Biodeter .Biodeg. 59 (2) : 73 -84 . 2007.

[26] Parshetti , G. ; Kalme , S. ; Saratale , G. ; Govinndwar, S. Biodegradation of malachite green by kocuriarosea MTCC 1532 . Acta .Chim. Siov., 53: 492 -498 .2006.

[27] Rania , M. A. A. Decolorization and Biodegradetion of crystal violet and Malachite green by Fusariumsolani ( Martius) saccardo . A comparative study on biosorption of dyes by the dead fungal biomass . American Eurasian . J. Botany . 1(2) : 17 31.2008 .
[28] Shedbalker , U. ; Dhanve , R. ;Jadhav , J . Biodegradation of triphenylmethane dye cotton blue by Penicilliumochrochloron MTCC . 517 . , J. Hazard .Mater ., 157: 472 -479 . 2008.

[29] Srivastava , S. ; Sinha , R. ; Roy , D. Toxicological effects of malachite green. Aquatic Toxicol .66 : $319-329.2004$.

[30]Tang , W. ; Jia , R. ; Zhang, D. Decolorization and degradation of synthetic dyes by Schizophyllum sp. F17 in anoval system, Desalination ; $265: 22-27$. 2011 .

[31] Tapalad , T. ; Neramittagapong , A. ; Neramittagapong, S. ; Boonmee, M. Degradation of Congo red dye by ozonation, Chiang Mai . J. Sci . , 35:63-68.2008.

[32]Zho , Y. , Min , Y. ; Qiao , H. , Huang ,Q. ;Wang , E. ; Ma, T. Improved removal of malachite green from aqueous solution using chemically modified cellulose by anhydride . J.BioIMacromoI .74 : 271277.2015 .

[33]Zollinger, H . Synthetic properties and applications of organic dyes and pigments . Color Chemistry. VCH Publisher, New York , 92-102 . 1987. 